\title{
Aplasia medular tratada exitosamente con ciclosporina en un paciente en hemodiálisis crónica
}

\author{
Jorge Vega $\mathrm{S}^{1,3}$, María de los Angeles Rodríguez $\mathrm{S}^{2}$, \\ Alejandro Vásquez $\mathrm{G}^{2}$, Carlos Torres $\mathrm{F}^{2}$. \\ Bone marrow aplasia \\ during hemodialysis successfully \\ treated with cyclosporine. \\ Report of one case
}

\begin{abstract}
A 28 years old male on chronic hemodialysis for 40 months due to a IgA crescentic glomerulonephritis developed pancytopenia (hematocrit $16 \%$, white blood cell count $3.800 \mathrm{~mm}^{3}$ and platelets $11.000 \mathrm{~mm}^{3}$. The bone marrow aspirate showed erythropoietic hyperplasia. Hemolytic anemia, folate or vitamin B12 deficiency and paroxysmal nocturnal hemoglobinuria were ruled out. Steroids were given with a transient elevation of red cells and platelets, which lasted only for some weeks. Afterwards, intravenous immunoglobulin was given without benefit. Two months after, a bone marrow biopsy and a bone marrow magnetic resonance imaging showed severe aplasia. Cyclosporine was started with a rapid increase in blood cells count. Eight months later, he received a renal transplant from a cadaveric donor. Immunosupression was achieved with cyclosporine, prednisone and mycofenolate mofetil. The patient required hemodialysis for the first three weeks and a mild acute cellular rejection was treated with methylprednisolone. At discharge, 6 weeks later, serum creatinine was $2.4 \mathrm{mg} / \mathrm{dl}$ and creatinine clearance $37.6 \mathrm{ml} / \mathrm{min}$. During the first months after transplant, platelet count and hemoglobin decreased and a bone marrow biopsy showed only mild hypoplasia. Four months after renal transplant the hematocrit was $43 \%$, white blood cell count $6.600 \mathrm{~mm}^{3}$ and platelets, $150.000 \mathrm{~mm}^{3}$ and did not change during the first year of follow up (Rev Méd Chile 2004; 132: 989-94).
\end{abstract}

(Key Words: Anemia, aplastic; Bone marrow; Glomerulonephritis, IgA; Pancytopenia)

Recibido el 15 de diciembre, 2003. Aceptado en versión corregida el 18 de mayo, 2004. Servicio de Medicina Interna, Secciones de Nefrología ${ }^{1}$, Hematología ${ }^{2}$, Hospital Naval Almirante Nef, Viña del Mar. Departamento de Medicina ${ }^{3}$, Escuela de Medicina, Universidad de Valparaíso.

Correspondencia a: Dr. Jorge Vega Stieb. 5 Norte 1035,

Viña del Mar, Chile. Fax 52-36-970050. E mail:

jvegastieb@hotmail.com 
L a aplasia de la médula hematopoyética es un trastorno poco frecuente y potencialmente mortal. Si bien puede asociarse al uso de sustancias químicas, radiaciones, medicamentos, enfermedades inmunológicas e infecciones virales, la mayonía de las veces es idiopática ${ }^{1}$. En estas últimas, mecanismos de autoinmunidad están involucrados y a menudo la terapia inmunosupresora logra revertina, mejorando en forma notable la sobrevida ${ }^{2-4}$.

Esta comunicación tiene por objeto dar a conocer el caso de un paciente en hemodiálisis crónica que desarrolló una aplasia medular seve- ra, la cual revirtió con el empleo de ciclosporina permitiendo posteriormente realizar un trasplante renal exitoso.

En la revisión de la literatura médica no encontramos ninguna publicación que informara de algún caso similar.

Caso clínico. Varón de 25 años que en julio de 1997 fue hospitalizado por hipertensión arterial severa $(220 / 110 \mathrm{mmHg})$ e insuficiencia renal avanzada sin evidencias de una enfermedad sistémica (Tabla 1). Los riñones eran de tamaño

Tabla 1. Exámenes de laboratorio de julio 1997

\begin{tabular}{|lc|}
\hline - Hematocrito (\%) & \\
- Hemoglobina (g/dl) & 34,5 \\
- Volumen corpuscular medio (u3) & 12,1 \\
- Concentración de hemoglobina corpuscular media (\%) & 94 \\
- Leucocitos (mm3) & 35 \\
- Plaquetas (mm3) & 10.800 \\
- Velocidad de eritrosedimentación (mm/hora) & 128.000 \\
- Creatinina (mg/dl) & 84 \\
- Urea (mg/dl) & 5,75 \\
- Ácido úrico (mg/dl) & 123 \\
- Clearence creatinina (ml/min/1,73m2) & 6,9 \\
- Proteinuria (g/24 horas) & 12,9 \\
- Calcio (mg/dl) & 6,25 \\
- Glucosa (mg/dl) & 8,37 \\
- Proté́nas (g/dl) & 85 \\
- Albúmina (g/dl) & 7,2 \\
- Globulinas (g/dl) & 4,1 \\
- Título de antiestreptolisina O (U.I./ml) (VN: <200) & 3,1 \\
- Complemento C'3 (g/l) (VN: 0,9-1,8) & 800 \\
- Complemento C'4 (g/l) (VN: 0,1-0,4) & 1,18 \\
- Sodio (mEq/L) & 0,43 \\
- Potasio (mEq/L) & 145 \\
- Cloro (mEq/L) & 5,4 \\
- Bicarbonato (mEq/L) & 114 \\
- Anticuerpos antinucleares & 23,1 \\
- Anticuerpos anti DNA & negativos \\
- Anticuerpos anticitoplasma de los neutrófilos & negativos \\
- Anticuerpos anti virus C de la hepatitis & negativos \\
- Antígeno de superficie del virus B de la hepatitis & negativos \\
- Anticuerpos anti virus de la inmunodeficiencia adquirida & negativos \\
- Anticuerpos IgG para citomegalovirus & negativos \\
- Anticuerpos IgG para Epstein Barr & positivos \\
- Inmunoglobulina G (g/l) & positivos \\
- Inmunoglobulina A (g/l) & 11,8 \\
- Inmunoglobulina M (g/l) & 4,52 \\
\hline & 2,56 \\
\hline
\end{tabular}


normal. Una biopsia mostró una glomerulonefritis crescéntica avanzada con depósitos de IgA y C'3. El paciente ingresó a hemodiálisis crónica tres semanas después. Posteriormente fue incorporado a la lista de espera de trasplante renal.

A los 40 meses en hemodiálisis comenzó a anemizarse, a pesar de recibir eritropoyetina 6.000 U semanales, hierro, complejo B y ácido fólico. En 8 meses, el hematocrito cayó de $29,6 \%$ a $16,9 \%$. Se descartó una hemorragia digestiva. Fue hospitalizado a los 48 meses de estar en hemodiálisis, constatándose leucopenia $\left(3.800 \mathrm{~mm}^{3}\right)$ y trombopenia severa $\left(11.000 \mathrm{~mm}^{3}\right)$ con un volumen corpuscular medio de $126 \mathrm{u}^{3}$. Se planteó una megaloblastosis o un síndrome de Evans. Los niveles de vitamina B12, ferritina y láctico deshidrogenasa estuvieron elevados y los de ácido fólico, test de Coombs, hemosiderina en orina, tiempo parcial de tromboplastina activada, protrombinemia, productos de degradación del fibrinógeno, antígeno de superficie del virus B de la hepatitis, anticuerpos para el virus de inmunodeficiencia adquirida y virus $\mathrm{C}$, anticuerpos antinucleares y anti ADN fueron normales o negativos. El mielograma mostró una médula hipercelular por hiperplasia eritroblástica $(58 \%)$ y el resto de las series normales. Una ecotomografía abdominal mostró un bazo de 12,2 por $6,6 \mathrm{~cm}$ y un bazo accesorio de 2,8 por $2,0 \mathrm{~cm}$.

El enfermo presentó insuficiencia cardíaca y sangrado de mucosas por lo que se inició, empíricamente, terapia esteroidal con $1 \mathrm{~g}$ de metilprednisolona por 3 días, seguido de prednisona $60 \mathrm{mg} /$ día. Ello produjo un ascenso en el hematocrito hasta $28,3 \%$ y de plaquetas hasta $66.000 \mathrm{~mm}^{3}$ en el lapso de una semana. Fue dado de alta recibiendo losartan, hierro, ácido fólico y prednisona (previo a la hospitalización recibía metildopa, hidralazina y sertralina, las que fueron suspendidas por la eventualidad de que tuvieran un rol en sus citopenias). Al mes siguiente, recibiendo prednisona, el hematocrito, los leucocitos y las plaquetas cayeron hasta $14 \%, 4.100 \mathrm{~mm}^{3}$ y $5.000 \mathrm{~mm}^{3}$, respectivamente. El recuento de reticulocitos fue $0,3 \%$ y el volumen corpuscular medio $106 \mathrm{u}^{3}$. Presentó hematuria macroscópica, epistaxis, equimosis y petequias difusas. Se hospitalizó y recibió transfusión de eritrocitos y plaquetas. Se sospechó una hemoglobinuria paroxística nocturna que se descartó por la normalidad del test de Ham y de sucrosa, reactividad normal de los monocitos para el antígeno CD14, CD55 y CD59 en eritrocitos y neutrófilos. Un segundo mielograma mostró importante reducción de la celularidad respecto al de 2 meses antes, con una serie eritroblástica proporcionalmente aumentada $(49,5 \%)$ y la megacariocítica disminuida acentuadamente. La biopsia de médula ósea mostró una hipoplasia marcada y escasos megacariocitos. Se diagnosticó una aplasia medular. Una resonancia nuclear magnética de la médula ósea mostró su reemplazo por tejido graso. Se inició terapia con gammaglobulina iv $25 \mathrm{~g} /$ día durante 6 días, la cual no tuvo ningún efecto.

El 27 de noviembre de 2001 se inició terapia con ciclosporina en dosis inicial de $6 \mathrm{mg} / \mathrm{kg} /$ día asociando luego ketoconazol, con el objeto de reducir el gasto en ciclosporina. Se observó una rápida respuesta con ascenso en las tres series desde la segunda semana de su empleo (Tabla 2). Meses después, se reincorporó al paciente a la lista de espera de trasplante renal.

El 7 de agosto de 2002 recibió un trasplante renal de un donante cadavérico. A la ciclosporina y ketoconazol se adicionó micofenolato mofetil $1.000 \mathrm{mg}$ y prednisona $60 \mathrm{mg}$ desde el primer día del trasplante. Evolucionó con una falla renal oligúrica por lo que continuó hemodializándose durante las primeras tres semanas. Una biopsia renal a los 14 días mostró evidencias de una necrosis tubular aguda en recuperación y un rechazo celular agudo leve. Se administraron 500 mg de metilprednisolona y en los días siguientes recuperó la diuresis retirándose la hemodiálisis.

Durante el primer mes del trasplante se produjo una caída importante en las tres series hematopoyéticas. Un mielograma y biopsia de médula ósea realizadas a los 30 días del injerto, mostraron a las tres series en proporción adecuada concluyéndose que existía una hipoplasia medular leve (Tabla 2). El paciente egresó a las 6 semanas del trasplante con creatinina de $2,4 \mathrm{mg} / \mathrm{dl}$ y un clearence de creatinina de $37,6 \mathrm{ml} / \mathrm{min}$. En los meses siguientes se produjo un ascenso progresivo de las tres series y a los 4 meses del injerto ellas estaban en rangos normales (Tabla 2). A los 10 meses del trasplante su hematocrito era $50 \%$, leucocitos $5.900 \mathrm{~mm}^{3}$, las plaquetas $270.000 \mathrm{~mm}^{3}$, creatinina $2,1 \mathrm{mg} / \mathrm{dl}$ y el clearence de creatinina $33 \mathrm{ml} / \mathrm{min}$. 
Tabla 2.

\begin{tabular}{|c|c|c|c|c|c|c|}
\hline \multicolumn{7}{|c|}{ Evolución del hemograma con el uso de ciclosporina en aplasia medular } \\
\hline Fechas & $27 / 11 / 01$ & 12/12/01 & $3 / 1 / 02$ & $1 / 2 / 02$ & $22 / 5 / 02$ & $15 / 7 / 02$ \\
\hline Hematocrito (\%) & 17,8 & 20,3 & 18,9 & 24,7 & 30,7 & 30,0 \\
\hline Hemoglobina ( $\mathrm{g} / \mathrm{dl})$ & 6,2 & 6,9 & 6,3 & 8,5 & 10,6 & 10,0 \\
\hline Volumen corpuscular medio (u3) & 99 & 107 & 115 & 112 & 109 & 110 \\
\hline Leucocitos (mm3) & 5.400 & 6.300 & 4.700 & 9.000 & 6.300 & 4.800 \\
\hline Basófilos (\%) & 0 & 0 & 0 & 0 & 1 & 0 \\
\hline Eosinofilos (\%) & 1 & 0 & 2 & 3 & 2 & 2 \\
\hline Baciliformes (\%) & 1 & 2 & 0 & 0 & 0 & 0 \\
\hline Segmentados (\%) & 48 & 63 & 53 & 74 & 76 & 56 \\
\hline Linfocitos (\%) & 41 & 28 & 36 & 17 & 16 & 33 \\
\hline Monocitos (\%) & 9 & 7 & 9 & 6 & 5 & 9 \\
\hline Plaquetas (mm3) & 18.000 & 38.000 & 77.000 & 112.000 & 90.000 & 87.000 \\
\hline VHS (mm/hora) & $>140$ & & $>140$ & $>140$ & 105 & 87 \\
\hline Dosis de CsA (mg/d) & 320 & 150 & 150 & 150 & 150 & 150 \\
\hline Dosis de ketoconazol (mg/d) & 0 & 200 & 200 & 200 & 200 & 200 \\
\hline Nivel de CsA Co (ng/ml) & & 110 & 315 & & & 112 \\
\hline Nivel de CsA C2 (ng/ml) & & & & 700 & 1.047 & \\
\hline \multicolumn{7}{|c|}{ Evolución del hemograma después del trasplante renal } \\
\hline Fechas & $7 / 8 / 02$ & $26 / 8 / 02$ & 9/9/02 & $7 / 10 / 02$ & $4 / 11 / 02$ & $2 / 12 / 02$ \\
\hline Hematocrito (\%) & 32,9 & 20,7 & 23,2 & 27 & 35,2 & 42,9 \\
\hline Hemoglobina $(\mathrm{g} / \mathrm{dl})$ & & 7,1 & 7,8 & 9,1 & 11 & 13,7 \\
\hline Volumen corpuscular medio (u3) & & 102 & 102 & 100 & 107 & 102 \\
\hline Leucocitos (mm3) & 10.500 & 8.300 & 4.300 & 7.000 & 5.900 & 6.600 \\
\hline Basófilos (\%) & 0 & 0 & 0 & 0 & 0 & 0 \\
\hline Eosinófilos (\%) & 2 & 0 & 1 & 5 & 0 & 1 \\
\hline Juveniles (\%) & 0 & 0 & 2 & 0 & 0 & 0 \\
\hline Baciliformes (\%) & 0 & 0 & 1 & 0 & 0 & 0 \\
\hline Segmentados (\%) & 70 & 95 & 84 & 53 & 62 & 68 \\
\hline Linfocitos (\%) & 25 & 1 & 10 & 38 & 36 & 24 \\
\hline Monocitos (\%) & 3 & 9 & 2 & 4 & 2 & 7 \\
\hline Plaquetas (mm3) & 102.000 & 43.000 & 25.000 & 94.000 & 125.000 & 150.000 \\
\hline VHS (mm/hora) & 108 & 94 & 88 & 101 & 42 & 38 \\
\hline
\end{tabular}

CsA Co: ciclosporina, concentración basal; C2: concentración a las dos horas de la dosis de ciclosporina.

\section{DISCUSIÓN}

El paciente, luego de 40 meses en hemodiálisis crónica, inició una anemización progresiva con macrocitosis (volumen corpuscular medio de 126 $\mathrm{u}^{3}$ ) asociada a leucopenia y trombocitopenia que hizo sospechar una anemia megaloblástica, si bien recibía suplementación de vitamina B12 y folatos. Esta hipótesis fue descartada por la ausencia de megaloblastosis medular y los niveles séricos de dichas vitaminas.

También se planteó una anemia hemolítica y trombopenia autoinmunes (síndrome de Evans). El uso de hidralazina y metildopa eran factores de riesgo para una anemia hemolítica. Ello no fue apoyado por el laboratorio dado que el test de Coombs y los anticuerpos antinucleares fueron negativos y no existía reticulocitosis. 
Una tercera posibilidad diagnóstica fue una aplasia pura de células rojas, la que se caracteriza por una anemia severa con volumen corpuscular medio normal o elevado, depósitos de hierro aumentados, ausencia de reticulocitos y de precursores enitroides en la médula ósea. La forma adquirida puede ser idiopática o asociarse a enfermedades autoinmunes, infecciones, uso de drogas, neoplasias hematológicas, tumores sólidos y durante el embara$\mathrm{zo}^{5}$. En estos trastomos se han aislado linfocitos T citotóxicos capaces de inducir apoptosis en las células troncales y de inhibir a las colonias eritroides en cultivos de células medulares de sujetos sanos ${ }^{6,7}$.

En los últimos años se ha descrito aplasia pura de células rojas en pacientes en hemodiálisis crónica que utilizan eritropoyetina recombinante humana ${ }^{8-10}$. Se produciría la formación de anticuerpos neutralizantes anti-eritropoyetina capaces de inhibir en cultivos in vitro la formación de colonias eritroides de células medulares de sujetos normales. La suspensión de la eritropoyetina y la terapia con ciclosporina y corticoides son capaces de revertir el trastorno ${ }^{10}$. En este paciente, en el mielograma inicialmente fue descrita una hiperplasia de la serie roja, lo que descartó una aplasia pura de células rojas. Es probable que la muestra haya sido de un islote de la médula en que la serie roja estaba menos afectada que las otras series, lo que simuló una hiperplasia eritropoyética. Si bien el bazo estaba ligeramente aumentado de tamaño, para lo que no tenemos una explicación, no se consideró que un hiperesplenismo fuera la causa de las citopenias. La trombopenia severa con sangramiento de mucosas y la presencia de megacariocitos normales en la médula indujo a utilizar corticoides, lo que produjo un incremento en el número de plaquetas en la primera semana de su uso, lo que incrementó la sospecha de una trombopenia inmunológica. Un mes después, estando con esteroides en dosis altas, recurrieron las citopenias lo que hizo plantear la hipótesis de una hemoglobinuria paroxística nocturna lo cual se

\section{REFERENCIAS}

1. BRodsky RA. Biology and management of acquired severe aplastic anemia. Curr Opin Oncol 1998; 10: 95-9. descartó. Por el fracaso del empleo de gammaglobulina ev, se repitió el mielograma y se efectuó una biopsia de médula ósea para conocer si habían cambios respecto a la practicada dos meses antes. Estas mostraron una aplasia medular severa. Por la sospecha de un mecanismo inmunológico, dada la buena respuesta inicial a los esteroides se inició terapia con ciclosporina ${ }^{1,2}$. Ella rápidamente tuvo un efecto beneficioso permitiendo al paciente reingresar a la lista de espera de trasplante renal.

Se ha planteado una teoría integradora para la aplasia medular que postula que el daño inducido por sustancias químicas, virus, drogas u otros antígenos, produciría una activación de linfocitos $\mathrm{T}$, produciendo una respuesta inhibitoria sobre las células troncales mediadas por citoquinas como interferón gamma e inducción de apoptosis ${ }^{11-16}$.

Las terapias para los pacientes con anemia aplástica son el trasplante de células hematopoyéticas y la terapia inmunosupresora. Como la mayoría no tiene un donante compatible, la segunda opción es la más frecuentemente empleada. Se han utilizado en forma aislada 0 combinada la timoglobulina, ciclosporina, los esteroides, los factores estimulantes de colonias, inmunoglobulina ev y la ciclofosfamida. Estudios recientes han comunicado que el uso combinado de los cuatro primeros logra remisiones en $77 \%$ de los pacientes a los 3 meses y sobrevidas actuariales de hasta $87 \%$ a los 5 años $1,2,17-19$.

Este paciente, gracias al empleo de ciclosporina logró superar su anemia aplástica, condición que no tenía ninguna relación con su nefropatía y recibir un trasplante renal exitosamente. Si bien en los primeros meses del trasplante renal hubo un deterioro en el recuento de plaquetas y anemia, éstos se revirtieron a los cuatro meses sin modificar la terapia. Es posible que el empleo del micofenolato pueda haber tenido un efecto frenador sobre la médula ósea especialmente durante el período en que la función renal no se había recuperado ${ }^{20}$. 
rine A: 11 years follow up of a randomized trial comparing treatments of aplastic anemia. Blood 2003; 101: 1236-42.

4. Bacigalupo A, Bruno B, Saracco P, Di Bona E, LoCASCIU山 A, LOCATEШ F ET AL. Antilymphocyte globulin, cyclosporine, prednisolone, and granulocyte colony stimulating factor for severe aplastic anemia: an update of the GITMO/EBMT study on 100 patients. European Group for Blood and Marrow Transplantation (EBMT) Working Party on Severe Aplastic Anemia and the Gruppo Italiano Trapianti di Midolio Osseo. Blood 2000; 95: 1931-4.

5. Young N. Aplastic anemia. Lancet 1995; 346: 228.

6. Gotic M, Basara N, Rlovic Z, Antunovic P, MarisavlJEVIC D, BRKIC S. Successful treatment of refractory pure red cell aplasia secondary to chronic lymphocytic leukaemia with cyclosporine A: a correlation between clinical and in vitro effects. Nouv Rev Fr Hematol 1994; 36: 307-9.

7. Tohda $\mathrm{S}$, Nara $N$, Tanikawa $\mathrm{S}$, Imai $\mathrm{Y}$, Murakami $\mathrm{N}$, Аокі N. Pure red cell aplasia following autoimmune haemolytic anaemia. Cell mediated suppression of erythropoiesis as a possible pathogenesis of pure red cell aplasia. Acta Haematol 1992; 87: 98-102.

8. Casadevall N, Nataf J, Viron V, Kolta A, Kiladjian J, MarTin-Dupont P. Pure red-cell aplasia and antierythropoietin antibodies in patients treated with recombinant erythropoietin. N Engl J Med 2002; 346: 469-75.

9. CASEDAVALL N. Antibodies against rHuEPO: native and recombinant. Nephrol Dial Transplant 2002; 17 Suppl 5: 42-7.

10. Chng W, TAN L, Lu T. Cyclosporine treatment for patients with $\mathrm{CRF}$ who developed pure red blood cell aplasia following EPO therapy. Am J Kidney Dis 2003; 41: 692-5.

11. Nistico A, Young NS. Gamma interferon gene expression in the bone marrow of patients with aplastic anemia. Ann Intern Med 1994; 120: 463.

12. Sloand E, Kim S, Maciejewski JP, Tisdale J, Foluman D, Young NS. Intracellular interferon-gamma in circulating and marrow $\mathrm{T}$ cells detected by flow cytometry and the response to immunosuppressi- ve therapy in patients with aplastic anemia. Blood 2002; 100: 1185.

13. Ismail M, GibSon FM, GoRdon-Smith EC, RutheFord TR. Bcl-2 and Bcl-x expression in the CD34+ cells of aplastic anaemia patients: relationship with increased apoptosis and upregulation of Fas antigen. Br J Haematol 2001; 113: 706.

14. Vibhuti Tripathy NK, Nityanand S. Massive apoptosis of bone marrow cells in aplastic anaemia. $\mathrm{Br} \mathrm{J}$ Haematol 2002; 117: 993.

15. Xu JL, Nagasaka T, NaKashima N. Involvement of cytotoxic granules in the apoptosis of aplastic anaemia. Br J Haematol 2003; 120: 850.

16. Maciejewski JP, Selueri C, Sato T, Anderson S, Young NS. Increased expression of Fas antigen on bone marrow CD34+ cells of patients with aplastic anemia. Br J Haematol 1995; 91: 245.

17. Rosenfeld S, Folmann D, NúNEzZ O, Young NS. Antithymocyte Globulin and Cyclosporine for Severe Aplastic Anemia: Association Between Hematologic Response and Long-term Outcome. JAMA 2003; 289: 1130.

18. Gluckman E, Rokicka-Milewska R, Hann I, Nikiforakis E, Tavakol F, Cohen-Scal S et al. European Group for Blood and Marrow Transplantation working Party for Severe Aplastic Anemia. Results and follow-up of a phase III randomized study of recombinant human-granulocyte stimulating factor as support for immunosuppressive therapy in patients with severe aplastic anaemia. Br J Haematol 2002; 119: 1075.

19. Marsh J, Schrezenmeier $H$, Marin P, Ilhan O, Lunngman P, McCann S et al. Prospective randomized multicenter study comparing cyclosporin alone versus the combination of antithymocyte globulin and cyclosporin for treatment of patients with nonsevere aplastic anemia. A report from the European Blood and Marrow Transplant (EBMT) Severe Aplastic Anaemia Working Party. Blood 1999; 93: 2191.

20. Engelen W, Verpooten G, Van Der Pianken M, Helbert M, Bosmans J, De Broe M. Four cases of red blood cell aplasia in association with the use of mycophenolate mofetil in renal transplant patients. Clin Nephrol 2003; 60: 119-24. 